Published by Al-Nahrain College of Medicine P-ISSN 1681-6579

E-ISSN 2224-4719

Email: iraqijms@colmed-alnahrain.edu.iq

http://www.colmed-alnahrain.edu.iq

http://www.iraqijms.net

Iraqi JMS 2018; Vol. 16(3)

\title{
Detection of Respiratory Syncytial Virus in Infants and Young Children with Chest Infection: A Comparison of Reverse Transcription-PCR Technique to Chromatographic Immunoassay and Enzyme Linked Immunosorbent Assay
}

\author{
Arwa M. A. Al-Shuwaikh ${ }^{1} P h D$, Suha H. Ali ${ }^{2} M S C$, Hala S. Arif ${ }^{3} C A B P$ \\ ${ }^{1}$ Dept. of Microbiology, College of Medicine, Al-Nahrain University, Baghdad, Iraq, ${ }^{2}$ Al Imamein Al-Kadhimein Medical \\ City, Baghdad, Iraq, ${ }^{3}$ Dept. of Pediatrics, College of Medicine, Al-Nahrain University, Baghdad, Iraq
}

\begin{abstract}
Background Human respiratory syncytial virus (hRSV) is a major cause of viral lower respiratory tract infection among infants and young children less than 2 years old. Multiple methods are used for the laboratory diagnosis of hRSV infections, including chromatographic immunoassay, enzyme linked immunosorbent assay (ELISA) and reverse transcription polymerase chain reaction (RT-PCR) technique for detection hRSV-antigens, hRSVantibodies and hRSV-RNA, respectively.

Objective To compare the efficiency of three diagnostic methods in detection of hRSV in infants and young children with chest infection.

Methods This study included 100 hospitalized infants and young children (39 females and 61 males) aged from (1) month to $(24)$ months, their mean age $(6.87 \pm 6.03)$ months, who required hospital admission at the Pediatric Department in Al-Imamein AL-Kadhimein Medical City Hospital, Central Teaching Pediatric Hospital, and AlKadhimiya Pediatric Hospital in Baghdad-Iraq. Samples were collected over a three-month winter period from January 2017 to April 2017. Fresh nasal swab specimens were collected and testes for hRSV antigens by using chromatographic immunoassay as a rapid test, in addition, nasopharyngeal/throat swabs specimens were processed for detection of hRSV-RNA by RT-PCR, both for direct detection. Also, ELISA was done to measure anti-hRSV IgM antibodies in serum for indirect detection of RSV infection.

Results hRSV was found to be positive in (27\%), (56\%) and (44\%) of specimens by rapid chromatographic immunoassay, ELISA and RT-PCR technique, respectively. Comparing with RT-PCR, the sensitivity of rapid test was (59.09\%) ranged from (44.41) to (72.31) and the specificity was (98.21\%) ranged from (90.55) to (99.91) with likelihood ratio equal to (33.09), while the sensitivity of ELISA test was (75.61\%) ranged from (60.66) to (86.17) and specificity was (59.62\%) ranged from (46.07) to (71.84) with likelihood ratio equals to (1.87).

Conclusion The RT-PCR technique was more sensitive than antigen or antibody detection methods for the diagnosis of hRSV

Keywords hRSV, rapid chromatographic immunoassay, ELISA, RT-PCR

Citation

Al-Shuwaikh AMA, Ali SH, Arif HS. Detection of respiratory syncytial virus in infants and young children with chest infection: a comparison of reverse transcription-PCR technique to chromatographic immunoassay and enzyme linked immunosorbent assay. Iraqi JMS. 2018; 16(3): 319-326. doi: 10.22578/IJMS.16.3.11
\end{abstract}

List of abbreviations: ELISA = Enzyme linked immunosorbent assay, hRSV = Human respiratory syncytial virus, RT-PCR = Reverse transcription polymerase chain reaction

\section{Introduction}

$\mathrm{H}$ uman respiratory syncytial virus (hRSV) is one of the major causes of viral respiratory tract diseases in infants and young children, with high rates of morbidity and mortality in infants and in the elderly (1). Severe hRSV bronchiolitis and pneumonia requiring hospitalization typically occur in infant less than 6 months of age (2). hRSV infections are usually symptomatic varying from a mild common cold to a life threatening 


\section{Al-Shuwaikh et al, Respiratory Syncytial Virus in Infants and Young Children}

that are characterized by worsening cough, tachypnea, dyspnea, hyperinflation, atelectasis, hypoxemia and increasing respiratory rate. It accounts for approximately $50 \%$ of all pneumonia and up to $90 \%$ of the reported cases of bronchiolitis in infancy ${ }^{(3)}$. Worldwide variation in the prevalence of respiratory viruses was reported to be between $2 \%$ and $78.6 \%{ }^{(4)}$. There are an estimated over 30 million cases per year, globally. However, in children younger than 5 years of age, the hRSV can causes very sever disease with more than 3.4 million hospital admissions and 66,000 to 199,000 deaths, most of whom occur in developed world ${ }^{(5-7)}$.

The virus is a globally ubiquitous respiratory pathogen of the genus Pneumovirus, within the family Paramyxoviridae and order Mononegavirales. hRSV has a single stranded, negative sense RNA genome ${ }^{(8)}$. The virus can spread by close contact with aerosols of infectious respiratory secretions and from medical staff who are often instrumental in its transmission ${ }^{(9,10)}$. In temperate climates the infection occurs as yearly winter epidemics. The first infection is usually the most severe but milder re-infections are common throughout life (11).

The laboratory diagnosis of hRSV infections is mostly done by rapid test ${ }^{(12,13)}$ and ELISA (14). The diagnosis can also be done by RT-PCR technique ${ }^{(15)}$. There are no approved vaccines against RSV infection; therefore, the management of severe infection of hRSV consists of supportive measures, such as oxygenation and maintenance of adequate hydration (16). Palivizumab, a monoclonal antibody approved against hRSV for prophylaxis to prevent and safe to treat hRSVrelated hospitalizations in high-risk children (1).

This study aimed to determine the frequency of hRSV in three hospitals in Baghdad city and to evaluate rapid test and ELISA in relation to RT-PCR in diagnosis of hRSV.

\section{Methods \\ Subjects}

In this descriptive cross-sectional study, 100 infants and young children were enrolled (39 females and 61 males) aged from (1) month to (24) months, their mean age was $(6.87 \pm 6.03)$ months, who required hospital admission at the Pediatric Department in Al-Imamein ALKadhimein Medical City Hospital, Central Teaching Pediatric Hospital, and Al-Kadhimiya Pediatric Hospital in Baghdad-Iraq. Samples collection was carried out from January to April, 2017. The study was approved by the Institutional Review Board (IRB) at Al-Nahrain College of Medicine and an informed consent was obtained from either parents of the child before they had been included in this study.

\section{Specimens collection}

Fresh nasal swabs were collected, stored in the refrigerator $\left(2-8{ }^{\circ} \mathrm{C}\right)$ and processed as soon as possible within 8 hours after collection for rapid detection of hRSV-Ag. Nasopharyngeal/throat swabs were collected and combined in universal transport medium (UTM) tube (Cat. No. 80346C, Copan, Italy). Each sample was liquated in cryotube (NuncKamstrup, Denmark) and stored at $\left(-80{ }^{\circ} \mathrm{C}\right)$ until testing by RT- PCR for detection of hRSVRNA. Two $\mathrm{ml}$ of blood were collected in serum separator tube (SST) and allowed to clot for 20 min. at room temperature before centrifugation at $1000 \times \mathrm{xg}$ for $15 \mathrm{~min}$. Then serum samples were liquated, immediately frozen and stored at $\left(-20^{\circ} \mathrm{C}\right)$ until screening by ELISA (Cat. No. CSB-E13790h, Cusabio, China) for anti-RSV IgM antibodies.

\section{Detection of hRSV-Ag by Rapid Chromatographic Immunoassay}

All (100) samples were tested for hRSV antigen in fresh nasal swab samples by one step card test, CerTest RSV Kit (CerTest Biotec, Spain). The procedure was done following the manufacturer's instructions. Nasal swab samples were prepared by placed into the testing tube, which supplied with the kit and shaking well. Four drops were dispensed into the samples (S) circulated window. After incubation at room temperature for $10 \mathrm{~min}$, the results were read by monitoring of colored 
development: Negative test; only one green line appears in the control line region. Positive test: In addition to the green control line, a red color line also appears in the test region.

\section{Detection of anti-hRSV IgM antibodies by ELISA}

Ninety-three samples were retested for antihRSV IgM by ELISA Kit (Cusabio, China). The micro titer plate was coated with antigen, indirect ELISA was used to capture anti-hRSV IgM from serum samples. The procedure was done following manufacturer's instructions. For sample preparation, serum samples were diluted by adding $10 \mu \mathrm{l}$ of the serum sample to $100 \mu$ of sample diluent which supplied with the kit. Blank, positive and negative control was included when the Kit was run. The optical densities (O.D.) of each well were measured at wave length $(450 \mathrm{~nm}$ and reference filter 630 $\mathrm{nm})$. The O.D. of the negative control less than 0.05 was calculated as 0.05 according to the manufacture. Then the O.D. of the sample was divided by O.D. of the negative control. AntiRSV IgM antibody ( $\geq 2.1$ ) considered as positive, while Anti-RSV IgM antibody (<2.1) considered as negative.

\section{Detection of hRSV-RNA by RT-PCR}

All 100 nasopharyngeal/throat swab samples were tested for the presence of hRSV-RNA by hRSV 298/550 IC Kit (Sacace Biotechnologies, Italy). To avoid possible contamination with exogenous sequences during extraction or amplification, all nucleic acid extraction, amplification, and detection steps were performed in separate laboratories. Negative and positive controls were extracted, reverse transcribed, and amplified in each batch of samples tested by PCR.

\section{Nucleic acid extraction}

Nasopharyngeal/throat processed samples were removed from deep freeze $\left(-80{ }^{\circ} \mathrm{C}\right)$ and thawed. After that, they were centrifuged at $10000 \mathrm{~g} / \mathrm{min}$ for $5 \mathrm{~min}$; the supernatant was discarded except $100 \mu \mathrm{l}$ of the solution was left to be used in re-suspension of the pellet for RNA extraction. The Ribo-Sorb nucleic acid extraction kit (Sacace Biotechnologies, Italy) was used for isolation and purification of RNA/DNA from samples. The procedure was done following manufacturer's instructions. Extracted RNA with purity in between (1.7-1.9) at absorption wavelength $260 / 280$ was included in this study, otherwise; RNA extraction of the sample was repeated. The RNA extracts were reverse transcribed to CDNA according to the manufacturer's instructions. Each obtained cDNA sample was diluted (1:2) with Tris-EDTA buffer solution and stored at $\left(-20{ }^{\circ} \mathrm{C}\right)$ for a week until cDNA amplification by $\mathrm{PCR}$, otherwise they were stored at $\left(-80^{\circ} \mathrm{C}\right)$ for longer periods storage.

\section{cDNA amplification}

DNA amplification reactions were carried out on target region L-gene by PCR according to manufacturer's instructions in three steps: first initial denaturation at $95^{\circ} \mathrm{C}$ for 5 min ( 1 cycle) and then the DNA amplification by sequentially heated for denaturation of DNA template at $95^{\circ} \mathrm{C}$ for $45 \mathrm{sec}$., annealing at $56^{\circ} \mathrm{C}$ for $45 \mathrm{sec}$. and extension at $72{ }^{\circ} \mathrm{C}$ for $45 \mathrm{sec}$. (42 cycles) and then final extension at $72{ }^{\circ} \mathrm{C}$ for $5 \mathrm{~min}(1$ cycle).

Interpretation of the results: Ten $\mu$ of PCR products were subjected to electrophoresis in agarose $(2 \%)$ in the presence of ethidium bromide and visualized under UV transilluminator. The band size was assessed by direct comparison with a 100-bp DNA marker. Analysis of PCR results is based on the presence or absence of specific bands of amplified DNA in agarose gel. The sample is considered to be positive for hRSV-RNA if the band of $298 \mathrm{bp}$ is observed on agarose gel. The presence of a $550 \mathrm{bp}$ fragment indicated positive result for internal control (IC) specific amplified DNA fragments

\section{Statistical analysis}

Data were analyzed using SPSS program (Statistical Package for the Social Sciences), versions 21 program for windows software package release 2013. Descriptive statistics were presented as frequencies, means and standard deviation (SD). Validity and predictability of different screening tests were 
assessed in relation to gold standard test by calculating sensitivity, specificity, predictive value of positive and negative test results.

\section{Results}

A total of 100 infants and young children with chest infection were included in this study. The male to female ratio was $1.5: 1$, their age ranging between $0-24$ months, most of the admitted patients were below 6 months. The clinical characteristics of enrolled patients were obtained from their hospital records; 40 (40\%) had pneumonia, 37 (37\%) had bronchiolitis and 23 (23\%) had other chest infection such as; cough, fever, shortness of breath, pertussis-like cough, wheezing and cyanosis, no case was recorded with croup or bronchitis, as shown in table (1).

Table 1. Demographic and clinical characteristics of the study population

\begin{tabular}{cc}
\hline Characteristics & No. of patients (\%) \\
\hline Gender & \\
\hline Males (M) & $61(61 \%)$ \\
Females (F) & $39(39 \%)$ \\
M:F ratio & $1.5: 1$ \\
Total & $100(100 \%)$ \\
\hline Age groups (months) & $62(62 \%)$ \\
\hline$[0-6]$ & $27(27 \%)$ \\
{$[7-12]$} & $11(11 \%)$ \\
{$[13-24]$} & $100(100 \%)$ \\
Total & $0(0 \%)$ \\
\hline Croup & $0(0 \%)$ \\
Bronchitis & $37(37 \%)$ \\
Bronchiolitis & $40(40 \%)$ \\
Pneumonia & $23(23 \%)$ \\
Other chest infection & $100(100 \%)$ \\
Total &
\end{tabular}

This study showed that hRSV was positive in $27 \%, 55.91 \%$ and $44 \%$ by Rapid test, ELISA and RT-PCR technique, respectively as shown in table (2) and figure (1).

Out of 100 samples, 27 (27\%) were hRSV-Ag positive by rapid test and 26 of these were positive for hRSV-RNA by RT-PCR, therefore, they were considered to be true positives, but one sample was negative for RT-PCR, therefore, it was considered to be false positive. Eighteen samples were PCR positive while negative for Rapid test for the purpose of defining the test characteristics were considered false negative. Given these definitions, the overall sensitivity of rapid test was $59.09 \%$ and specificity was $98.21 \%$. The positive predictive value was $96.3 \%$ with confidence interval $(\mathrm{Cl})$ ranged between (81.72-99.81), and the negative predictive value was $75.34 \%, \mathrm{Cl}=64.36-83.8)$. Also, antihRSV IgM Ab was identified by ELISA in only 93 samples; 52 (55.9\%) out of 93 were ELISA positive sera, 31 of these sera were hRSV-RNA positive, therefore, they were considered to be true positives, while 21 of these sera was negative by RT-PCR, therefore, they were considered to be false positive. Ten of these samples were positive for hRSV-RNA, while negative in ELISA test, therefore, were considered to be false negative. Accordingly, 
the overall sensitivity of ELISA test was $75.61 \%$ and specificity was $59.62 \%$. The positive predictive value was $59.62 \%, \mathrm{Cl}=(46.07-$
71.84), and the negative predictive value was $75.61 \%, \mathrm{Cl}=(60.66-86.17)$, as show in table (3).

Table 2. Results of hRSV detection in infants and young children with chest infection by three diagnostic methods: rapid test, ELISA and RT-PCR technique

\begin{tabular}{cccc}
\hline Methods of Diagnosis & No. of Positive (\%) & No. of Negative (\%) & Total (\%) \\
\hline Rapid test & $27(27.0 \%)$ & $73(73.0 \%)$ & $100(100 \%)$ \\
ELISA & $52(55.91 \%)$ & $41(44.09 \%)$ & $93(100 \%)$ \\
RT-PCR & $44(44.0 \%)$ & $56(56.0 \%)$ & $100(100 \%)$ \\
\hline
\end{tabular}

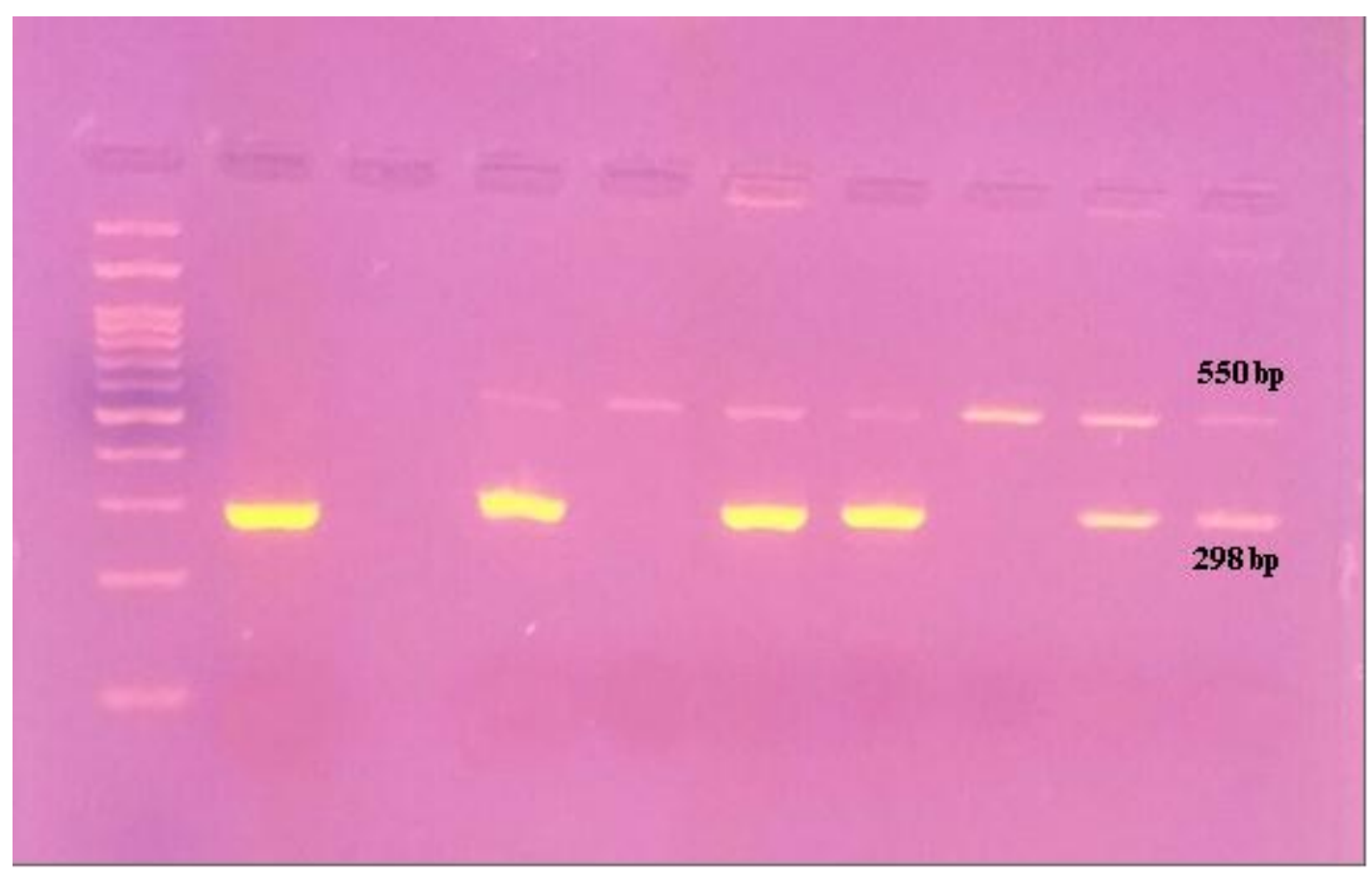

Figure 1. Gel-electrophoresis of PCR products of hRSV from Nasopharyngeal/throat swab sample using $2 \%$ agarose in TBE buffer. Lane 1, DNA marker (100-3000 bp ladder); Lane 2, hRSV cDNA $(\mathrm{C}+)$ serves as positive control for amplification; Lane 3, DNA- buffer (C-) serves as negative control for amplification; Lane 4, 6, 7,9,10 PCR products from patient positive for hRSV-RNA; Lane 5, 8 PCR products from patient negative for hRSV-RNA 
while the specificity of Rapid test was (98.21\%) ranged from (90.55\% to $99.91 \%$ ), with positive likelihood ratio 33.09. There are a number of factors that affect the sensitivity and specificity of an assay for viral detection, these include; Low viral copy number in the clinical sample, quality of the specimen and reagents, laboratory technician experience, transport conditions of the sample, suitability of the assay to specific populations (e.g., rapid antigen test in elderly versus young people), inter- and intra-laboratory standardization, and prevalence of the virus in the community ${ }^{(17,22)}$.

\section{Comparison of ELISA and RT-PCR for diagnosis hRSV}

In this study, 93 sera were screened for antihRSV-IgM antibodies by ELISA, 52 (55.91\%) of these 93 were sera positive and 21 out of these 52 were negative on RT-PCR and considered to be false positive, which might be explained by sera samples were collected after viral RNA had cleared or the time before evaluation was longer for the hospitalized patients (23). Another explanation on PCR negative result is that almost all children are negative by RT-PCR after 14-21 days, similar results reported by ${ }^{(24)}$, who found that anti-hRSV IgM antibody was detected in higher prevalence than hRSV-RNA ( $81.9 \%$ vs. $1 \%)$. In addition, IgM antibody positive result might represent cross-reactive antibodies causing false positive anti-hRSV results. This may be due to serologic crossreactions between the hRSV and other respiratory viruses ${ }^{(25)}$. Serology is not $100 \%$ sensitive and not always able to accurately determine the stage of infection since false positive and false negative results are regularly observed ${ }^{(22)}$. In the present study, 10 patients out of 41 (24.39\%) was RSV-RNA positive, but did not show a rise in anti-hRSV IgM antibody level we considered to be false negative. This study showed that the sensitivity of ELISA was (75.61\%) ranged from (60.66\% to $86.17 \%)$, while the specificity was (59.62\%) ranged from (46.07\% to $71.84 \%)$, with positive likelihood ratio 1.872 , therefore, ELISA technique was mostly performed to obtain seroepidemiologic information and for research purposes (26).
The present study confirms that rapid test and ELISA technique were less sensitive comparing with RT-PCR for detection of hRSV in infants and young children $\leq 2$ years of age with chest infection, and indicate that the golden standard RT-PCR is more sensitive, and specific method for detection of hRSV in comparison to serological tests.

\section{Acknowledgments}

To Ms. Asifa A. Hussein and the staff members in Central Teaching Pediatric Hospital, AlImamein Al-kadhimein Medical City Hospital, Al-Kadhimiya Pediatric Hospital and Al-Nahrain Medical Research Unit for their assistance in samples collection.

\section{Authors' contribution}

All authors contributed to this manuscript. Dr. Al-Shuwaikh: design, interpreted and arranged this manuscript. Ali: performed all the laboratory work, implementation and progress of this study. Dr. Arif: helped in clinical aspect and collection of samples.

\section{Conflict of interest}

There is no conflict of interest.

\section{Funding}

Self-funding.

\section{References}

1. Sharma A, Wu W, Sung B, et al. Syncytial Virus (RSV) pulmonary infection in humanized mice induces human anti-rsv immune responses and pathology. J Virol. 2016; 90(10): 5068-74. doi: 10.1128/JVI.0025916.

2. Zahran WA, Makled AF, Salama AA, et al. Comparison of Reverse Transcription-PCR and Viral Culture. Egyptian J Med Microbiol. 2017; 26 (2): 27-36.

3. Odisho SM, Al-Bana AS, Yaassen NY. Isolation and identification of Respiratory syncytial virus from Infants with histopathological studies of the isolated virus on experimental animals. Iraqi J Med Sci. 2010; 8(1): 2-10.

4. Al-Toum R, Bdour S, Ayyash H. Epidemiology and Clinical Characteristics of Respiratory Syncytial Virus Infections in Jordan. J Trop Pediatr. 2006; 52(4): 2827. doi: 10.1093/tropej/fml002.

5. Oladokun R, Muloiwa R, Hsiao NY, et al. Clinical characterization and phylogeny of respiratory syncytial virus infection in hospitalized children at Red Cross War Memorial Children's Hospital, Cape 
Town. BMC Infect Dis. 2016; 16: 236. doi: 10.1186/s12879-016-1572-5.

6. Checchia PA, Paes B, Bont $L$, et al. Defining the risk and associated morbidity and mortality of severe respiratory syncytial virus infection among infants with congenital heart disease. Infect Dis Ther. 2017; 6(1): 37-56. doi: 10.1007/s40121-016-0142-x.

7. Griffin MP, Khan, AA, Esser, MT, et al. Safety, tolerability, and pharmacokinetics of MEDI8897, the respiratory syncytial virus prefusion F-targeting monoclonal antibody with an extended half-life, in healthy adults. Antimicrob Agents Chemother. 2017; 61(3). pii: e01714-16. doi: 10.1128/AAC.01714-16.

8. Noton SL, Deflubé $L R$, Tremaglio $C Z$, et al. The respiratory syncytial virus polymerase has multiple RNA synthesis activities at the promoter. PLoS Pathog. 2012; 8(10): e1002980. doi: 10.1371/journal.ppat.1002980.

9. Lee YI, Peng CC, Chiu NC, et al. Risk factors associated with death in patients with severe respiratory syncytial virus infection. J Microbiol Immunol Infect. 2016; 49(5): 737-742. doi: 10.1016/j.jmii.2014.08.020.

10. Alhmairy, EH. Effectiveness of Palivizumab in preventing RSV hospitalization in high risk infants with CHD \& premature infants. Int J Adv Res. 2017; 5(3), 1583-96. doi:10.21474/IJAR01/3667.

11. Rida MF. Risk factors for respiratory syncytial virus (rsv) bronchiolitis in children. A hospital Based Study. Iraqi Postgrad Med J. 2011; 10 (3): 305-10.

12. Hall CB. Respiratory syncytial virus and parainfluenza virus. N Engl J Med. 2001; 344: 1917-28. doi: 10.1056/NEJM200106213442507.

13. Hall CB, Weinberg GA, Iwane MK, et al. The burden of respiratory syncytial virus infection in young children. $\mathrm{N}$ Engl J Med. 2009; 360(6): 588-98. doi: 10.1056/NEJMoa0804877.

14. Verhoeven D, Xu Q, Pichichero M E. differential impact of respiratory syncytial virus and parainfluenza virus on the frequency of acute otitis media is explained by lower adaptive and innate immune responses in otitis-prone children. Clin Infect Dis. 2014; 59(3): 376-83. doi: 10.1093/cid/ciu303.

15. Loeffelholz M, Chonmaitree T. Advances in diagnosis of respiratory virus infections. Int J Microbiol. 2010; 2010: 126049 . doi: 10.1155/2010/126049.

16. Whelan B, Musters E, Murray A, et al. Review of the home care programmes for respiratory syncytial virus (RSV) prophylaxis in Ireland and The Netherlands. Drugs Ther Perspect. 2016; 32(3): 119-30. doi: 10.1007/s40267-015-0275-0.

17. Henrickson KJ, Hall CB. Diagnostic assay for respiratory syncytial virus disease. Pediatr Infect Dis
J. 2007; 26(11 Suppl): S36-40. doi: 10.1097/INF.0b013e318157da6f.

18. Al-Charrakh AH, Al-Mola GA, Al-Azzawi JAT. Detection of human respiratory syncytial virus associated with asthmatic patients using tissue culture and real time - polymerase chain reaction. AL-Qadisiyha J Sci. 2016; 21(2).

19. Heikkinen T, Marttila J, Salmi AA, et al. Nasal Swab versus Nasopharyngeal Aspirate for Isolation of Respiratory Viruses. J Clin Micro. 2002; 40(11): 43379. Doi: http://dx.doi.org/10.1128/JCM.40.11.43374339.2002.

20. Gregson D, Lloyd T, Buchan S. et al. Comparison of the RSV Respi-Strip with direct fluorescent-antigen detection for diagnosis of respiratory syncytial virus infection in pediatric patients. J Clin Microbiol. 2005; 43: 5782-3. doi: 10.1128/JCM.43.11.5782-5783.2005.

21. Barati $M$, Talebi-Taher $M$, Noorbakhash $S$, et al. Diagnosis of the adenovirus, RSV, and influenza virus by rapid detection test (immunochromatography) in children with acute respiratory infection. J Comprehen Pediat. 2010; 2(2): 79-83.

22. Henrickson KJ. Advances in the laboratory diagnosis of viral respiratory disease. Pediatric Infect Dis J. 2004; 23(1 Suppl): S6-10 doi: 10.1097/01.inf.0000108187.63151.ea.

23. Falsey AR, Walsh EE. Respiratory syncytial virus infection in adults. Clin Microbiol Rev. 2000; 13: 37184.

24. AL-Bashar SH, Badawy AS, Mohammed BAR. Real time-PCR, ELISA, as identification methods for detection respiratory syncytial virus in children. Tikrit J Pure Sci. 2017; 22(2): 33-42.

25. Zhang Y, Pohl J, Brooks WA, et al. Serologic crossreactions between nucleocapsid proteins of human respiratory syncytial virus and human metapneumovirus. J Clin Microbiol. 2015; 53(5): 1609-15. doi: 10.1128/JCM.03649-14.

26. Popow-Kraupp T, Aberle JH. Diagnosis of respiratory syncytial virus infection. Open Microbiol J. 2011; 5: 128-34. doi: 10.2174/1874285801105010128.

Correspondence to Dr. Arwa M. A. AlShuwaikh

E-mail: arwa.mujahid@colmedalnahrain.edu.iq,

arwa_alshwaikh_2004@yahoo.com

Received Nov. $22^{\text {nd }} 2017$

Accepted Jan. $21^{\text {st }} 2018$ 